\title{
The Pathobiology of Skin Aging
}

\section{New Insights into an Old Dilemma}

\author{
Eleanor Russell-Goldman and George F. Murphy
}

From the Program in Dermatopathology, Department of Pathology, Brigham and Women's Hospital and Harvard Medical School, Boston, Massachusetts

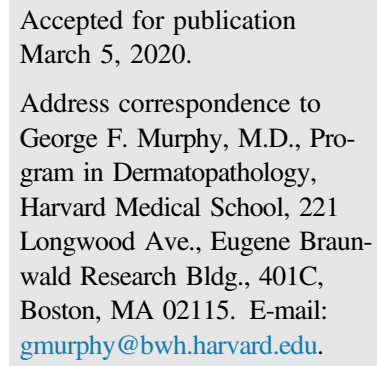

Long considered both physiologic and inevitable, skin aging is a degenerative phenomenon whereby both intrinsic and environmental factors conspire to produce an authentic disease. The consequences of this disorder are many and varied, ranging from atrophy and fragility to defective repair to deficient immunity and vulnerability to certain infections. The pathobiologic basis for skin aging remains poorly understood. At a cellular level, stem cell dysfunction and attrition appear to be key events, and both genetic and epigenetic factors are involved in a complex interplay that over time results in deterioration of our main protective interface with the external environment. Past and current understanding of the cellular and molecular intricacies of skin aging provide a foundation for future approaches designed to thwart the aging phenotype. Herein, the authors provide a review of current insights into skin aging, including the mechanisms of skin aging, the role of stem cells in skin aging and the implications of skin aging for the microbiome and for the development of cancer. Conquest of the oft overlooked disease of skin aging should have broad implications that transcend the integument and inform novel approaches to retarding aging and age-related dysfunction in those internal organs that youthful skin was designed to envelop and safeguard. (Am J Pathol 2020, 190: 1356-1369; https:// doi.org/10.1016/j.ajpath.2020.03.007)
Skin aging is not merely an issue of integumentary laxity. Rather, it encompasses deficiencies in immunity, the ways that we interact and equilibrate with microorganisms in our environment, our threshold for developing potentially lethal forms of cancer, the way we heal traumatic wounds, and the health and wellbeing of the very stem cells that maintain the organ that is our main interface with the external world. Moreover, a plethora of cellular players and biological pathways serves, not only as a paradigm for how factors internal and external to the skin conspire to produce pathologic aging phenotype and dysfunction, but also as a platform upon which we may now begin to understand aging in extracutaneous tissues.

This review explores some of the more recent insights into skin aging in the hope of developing a unified model for how skin changes over time, and how these changes affect the overall wellbeing of the organism as a whole. In so doing, pathologists and biologists may become increasingly aware of the importance of how skin serves as a model for how time transforms human tissues, and how this metamorphosis transcends the most trivial aspect of the condition of biological cutaneous aging (wrinkles) and implicates the two primary external enemies of cutaneous juvenescence: radiation and infection.

\section{Why Biological Skin Aging Is a Disease}

Defining a disease is not an easy task, as it encompasses a variety of factors that include historical perspectives, societal and cultural health expectations, diagnostic sensitivities and thresholds, and socioeconomic issues. Osteoporosis, considered to be a potentially integral component of a long life, became a disease in 1994 when it was converted from

Supported by the LEO Foundation grant LF-OC-19-000256 (G.F.M.) and National Cancer Institute (NCI) HTAN Initiative grant 1U2CCA233262-01 (G.F.M.).

Disclosures: None declared. 
being an unavoidable part of so-called normal aging to a pathologic condition. ${ }^{1}$ We would aver that intrinsic biological, and certainly environmentally enhanced, skin aging involves a major disease component simply because not all individuals are similarly affected, and the consequences of aging skin have serious implications for the health and wellbeing of the organism as a whole. Indeed, it may be argued that our skin is truly normal, or nearly so, only once in our lifetime: the day we are born. Because the skin is at the front line of many external insults throughout life, one could argue that skin aging is largely a result of this sustained environmental assault. However, studies have shown that the skin robustly mirrors aging in more internal human tissues. ${ }^{2}$ Profiling studies comparing expression of genes in old skin versus young skin from sun-protected sites reveals dysregulation of numerous cellular functions in aging skin including those involved in maintenance of the cytoskeleton, the immune response, and various metabolic pathways. ${ }^{3,4}$ Throughout life, genetic, epigenetic, microbiomic, and proteomic aberrations accrue, taking their cumulative toll-in the beginning at clinically covert molecular levels. Gene expression profiles also differ significantly in some individuals who appear to be relatively resistant to eventual skin aging. ${ }^{5}$ Moreover, chronological and environmentally induced components of skin aging are difficult to separate, ${ }^{6}$ and certain defects in skin that accompany skin photoaging (eg, immune cell depletion) may be partially corrected with therapy. ${ }^{7}$

Recognition of skin aging as a disease is also advantageous to public health and research efforts. Awareness of strategies to minimize the progression of this disease, including a healthful diet, avoidance of UV light (both natural and artificial), and other measures to cultivate a functionally responsive integument (including minimizing potentially harmful injectables for short-term cosmetic gain) are of key importance. And funding support aimed at thwarting the functional deficiencies of aging skin, including deficient wound healing (a major problem globally), is enhanced by the appropriate recognition of cutaneous aging as a disease with which society must reckon. Like any pathologic condition, skin aging also takes its toll on affected individuals psychologically, and this aspect of the disorder is often both overlooked or frankly ignored. ${ }^{8}$

\section{The Structural Realities of Chronologic Aging Versus Photoaging}

Whereas not all organs show overt structural/gross pathologic findings of aging, the skin regularly, albeit variably, shows the clinical ravages of time. Despite the mirth and laughter of wrinkles, what is going on under the wrinkled surface when skin is pathologically altered during an individual lifetime is no laughing matter. Figure 1 provides a histochemical overview that compares some of the salient structural and compositional attributes of the aged skin phenotype through examination of sun-exposed (face) and non-sun-exposed (lower abdomen) skin from subjects who are vicenarians (in the third decade) and octogenarians (in the ninth decade). One of the first alterations that occurs with age and that appears independent of repeated exposure to UV light is thinning of the epidermal layer associated with loss of epidermal rete ridges. This change is accompanied by attenuation and loss of dermal papillae that undulate with rete ridges and that contain the delicate capillary loops in part responsible for epidermal nourishment. The attenuation of the rete ridges also results in a decreased capacity of the skin to resist shearing forces, commonly illustrated by the comparative difficulty in removing a band aid from the skin of an elderly person versus the skin of a child without incurring epidermal disruption or associated hemorrhage. There is an additional, more subtle alteration in the dermis that also appears to be independent of UV exposure, namely less compacted collagen bundles in the reticular dermis in association with age. Recent insights have now established that over time, old dermal fibroblasts lose their identity, showing reduced expression of genes involved in the formation of extracellular matrix and acquiring proadipogenic traits, alterations that in experimental animals respond to metabolic influences that include caloric restriction. ${ }^{\text {? }}$

The epidermis plays major roles in the maintenance of homeostasis, and it protects us from physical, chemical, and infectious insults. As the site of eccrine gland secretion, the epidermis also plays an important role in thermoregulation, which when perturbed, can lead to dehydration with potentially serious consequences, particularly in the elderly population. The underlying dermis is crucial for the structural maintenance of skin integrity. Changes in all layers of the skin contribute to the visual signs of aging and to pathologic conditions associated with aging. Although, in general, the skin provides a protective barrier to many noxious physical and chemical agents, upon closer inspection, certain protective functions are compromised with aging.

The stratum corneum, the outermost layer of the epidermis, consists of corneocytes arranged in compact sheets that are embedded in an extracellular matrix derived from lamellar granules forming lipid-rich membranes. ${ }^{10,11}$ This cornified layer acts as the outermost interface between the atmosphere and the underlying epidermal and dermal tissues. The thickness of the stratum corneum can be dynamic throughout life, and it can become thickened in response to various insults or inflammatory conditions. However, studies have shown that the overall thickness of the stratum corneum between young and old skin does not significantly differ. ${ }^{12}$ Nonetheless, it is clear that there is a functional difference in the stratum corneum of young versus old skin because recovery of aged skin from insults to this layer are significantly slower than those seen in young skin, and permeability to certain substances is altered. ${ }^{13} \mathrm{~A}$ recent study examining the biochemical characteristics of the stratum corneum in aged skin from 

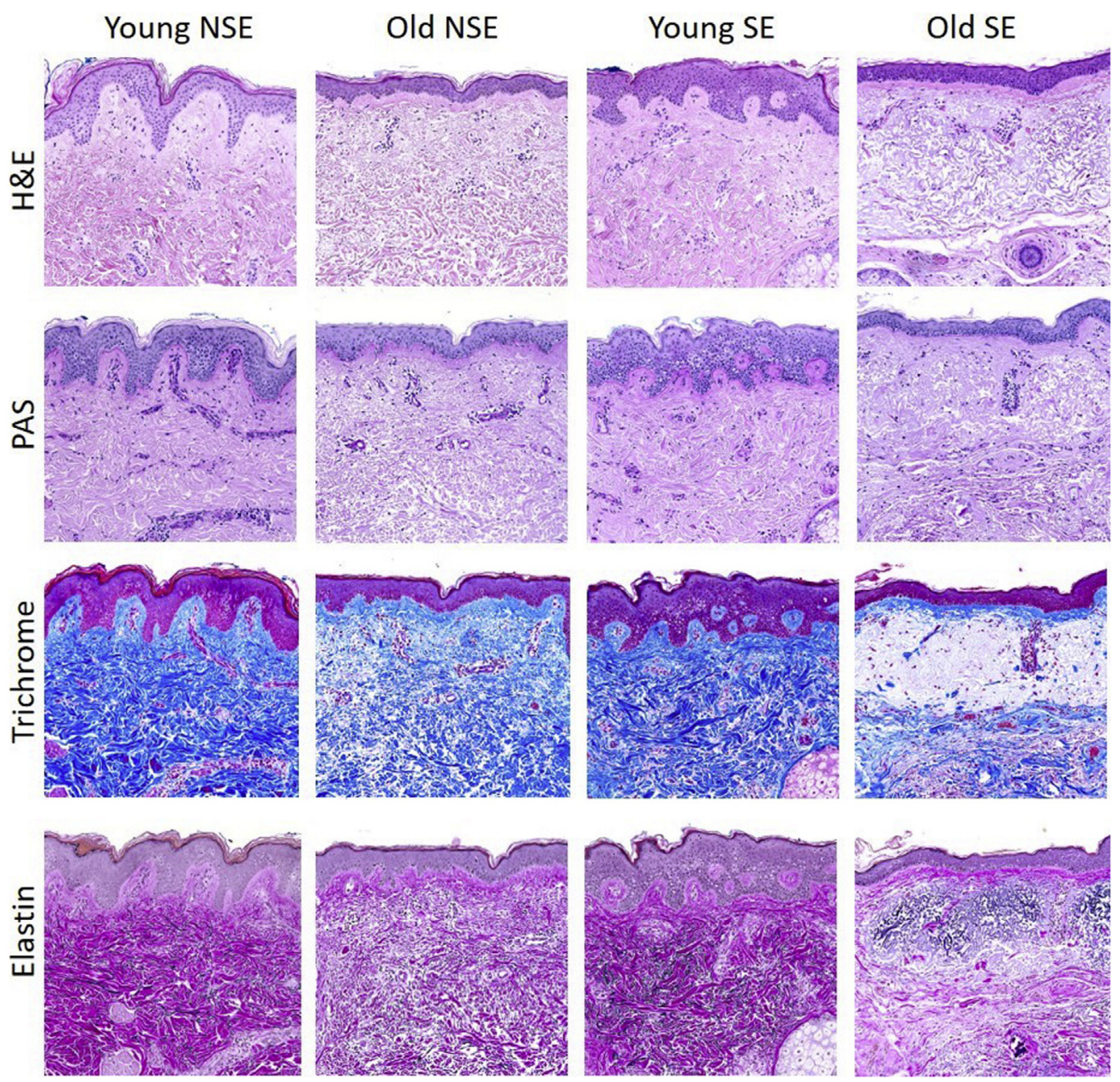

Figure 1 Histologic and histochemical survey of relatively young adult skin (29 years old) from face [chronically sun-exposed (SE)] and abdomen chronically non-sun-exposed (NSE), and relatively old skin (84 and 88 years old). By hematoxylin and eosin (H\&E) and periodic acid-Schiff (PAS) staining, there is striking epidermal thinning with loss of the rete ridges in old skin independent of site/chronic UV exposure. In addition, note that old skin, again independent of site/chronic UV exposure, is characterized by less dense, less intensely stained reticular dermal collagen. The diminution of dermal collagen density in old skin is further confirmed by trichrome and elastin stains, which also disclose significant replacement of the uppermost dermis by markedly abnormal elastic fibers (so-called solar elastosis) only in the chronically sun-exposed facial skin, but not in the more photo-protected abdominal skin, of the older individual. Original magnification, $\times 10$.

sun-protected sites revealed that stiffening of this layer occurs with aging, with increasing cellular cohesion due to altered lipid structure and decreased concentration of intercellular lipids. ${ }^{14}$ The kinetics of water movement through the stratum corneum is also decreased..$^{14}$ These changes, in addition to alterations in sebum secretion, likely play a role in common diseases of the elderly skin, notably xerosis.

The epidermis, composed of a keratinized stratified squamous epithelium with associated melanocytes, Langerhans cells, and Merkel cells, becomes significantly thinner with age. ${ }^{15}$ Studies using in vivo confocal microscopy to evaluate skin characteristics have found that aging skin displays altered keratinocytes with an irregular architectural pattern of keratinocyte and melanocyte distribution in comparison to younger skin. ${ }^{16}$ Flattening of the dermal-epidermal junction is also seen in aged skin, which corresponds with a decrease in the number of dermal papillae seen with in vivo microscopy. ${ }^{17}$ This decrease in vasculature providing nutrients to the epidermis may explain some of the degenerative changes observed in the epidermis of aged skin. Collagen and elastin, two of the main constituents of dermal tissue, also become altered over time. In intrinsically aged skin, the quantity of dermal collagen decreases, and elastin accumulates structural abnormalities. ${ }^{18}$ Some studies have estimated that the amount of dermal collagen present in sun-protected skin of adults aged over 80 years is $75 \%$ less than that present in the skin of young adults. ${ }^{19}$ Dermal fibroblasts are responsible for the production of collagen, elastin, and many extracellular matrix proteins in the skin. Electron microscopy studies have shown that fibroblasts from the papillary dermis of aged skin are large and irregular in shape with prominent cisternae of rough endoplasmic reticulum, ${ }^{12}$ changes that are possibly attributable to oxidative damage. ${ }^{20}$ The production 

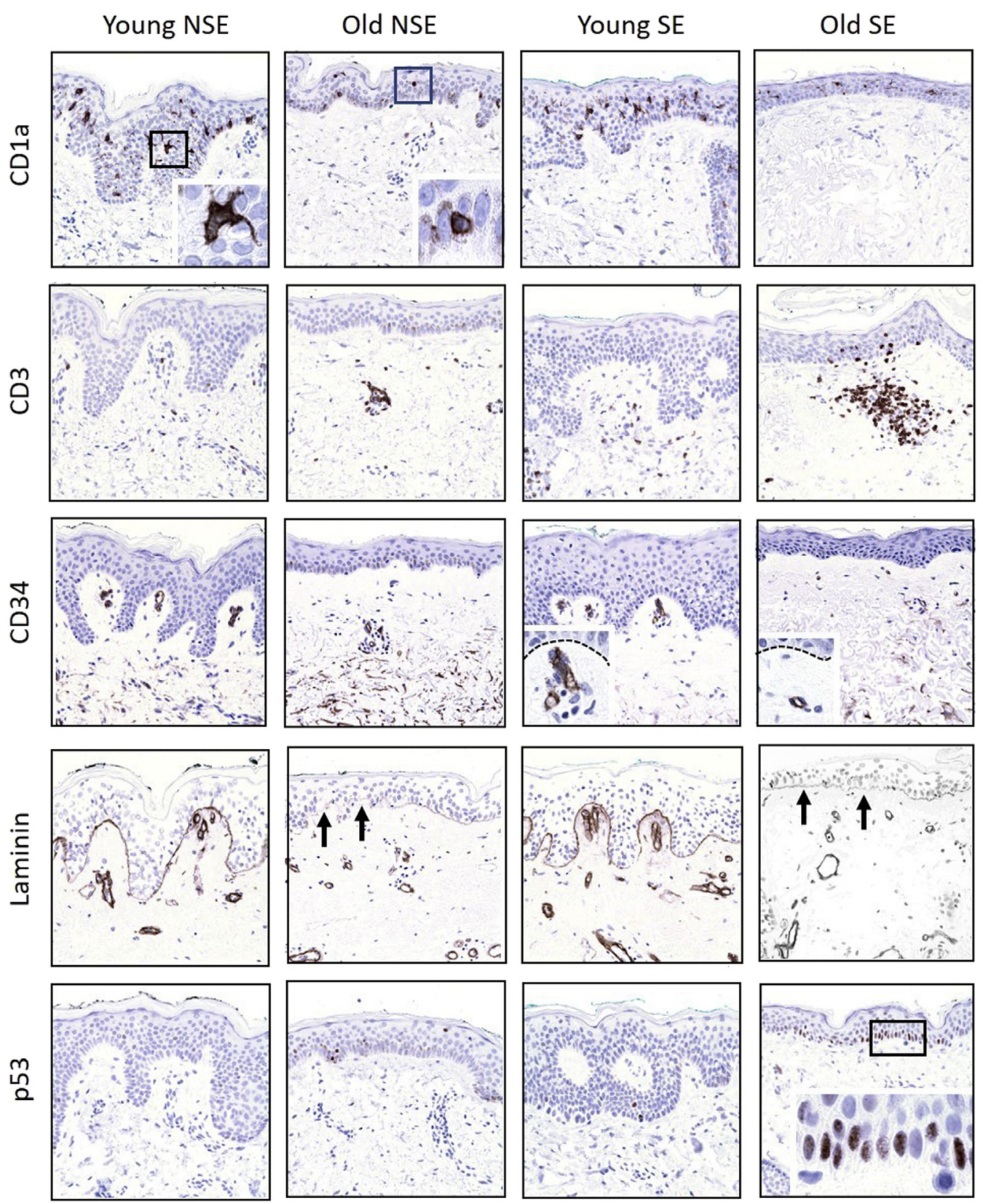

Figure 2 Immunohistochemical overview of sun-exposed (SE) and non-sun-exposed (NSE) skin from young and old patients characterized in Figure 1. Note depletion of CD1a-expressing epidermal Langerhans cells in relationship to age (independent of sun exposure) and altered cytology from more dendritic to rounded contours (boxed areas, shown in higher magnification in the insets). Sun-exposed old skin tends to harbor more CD3-expressing T cells, consistent with previously described heliodermatitis (Aging and Skin Immune Cells), and CD34 and laminin stains confirm loss of capillary loops (arrows) and superficial dermal microvascular density as a function of age. Dashed lines highlight the basement membrane with papillary dermal capillary loops below highlighted by CD34 immunostain (insets). Finally, discrete zones of p53 staining, consistent with mutant forms, are observed only in aged, sun-exposed epidermis, predominantly in the basal cell layer (boxed area). Original magnification, $\times 10$ (main images); $\times 40$ (insets).

of fibrillar type I and III collagen is most affected by chronological aging, and in addition, fragmentation and disorganization of collagen also occurs. ${ }^{21}$ The changes seen in collagen in aging skin are a result of decreased fibroblast proliferation with decreased production of new collagen in conjunction with an increased production of matrix metalloproteinases (MMP), notably MMP-1. ${ }^{19,22}$ The senescenceassociated secretory phenotype is a complex phenotype that arises in aged skin due to the secretion of numerous cytokines and other effector molecules, such as proteases and growth factors, from senescent skin fibroblasts. ${ }^{23}$ The senescence-associated secretory phenotype plays a role specifically in skin aging through the secretion of MMPs leading to collagen breakdown. Interestingly, evidence has shown that high molecular weight collagen fragments themselves inhibit new collagen synthesis, resulting in a possible negative feedback loop of collagen production in aged skin. ${ }^{24}$ Additionally, collagen fragments produced by 


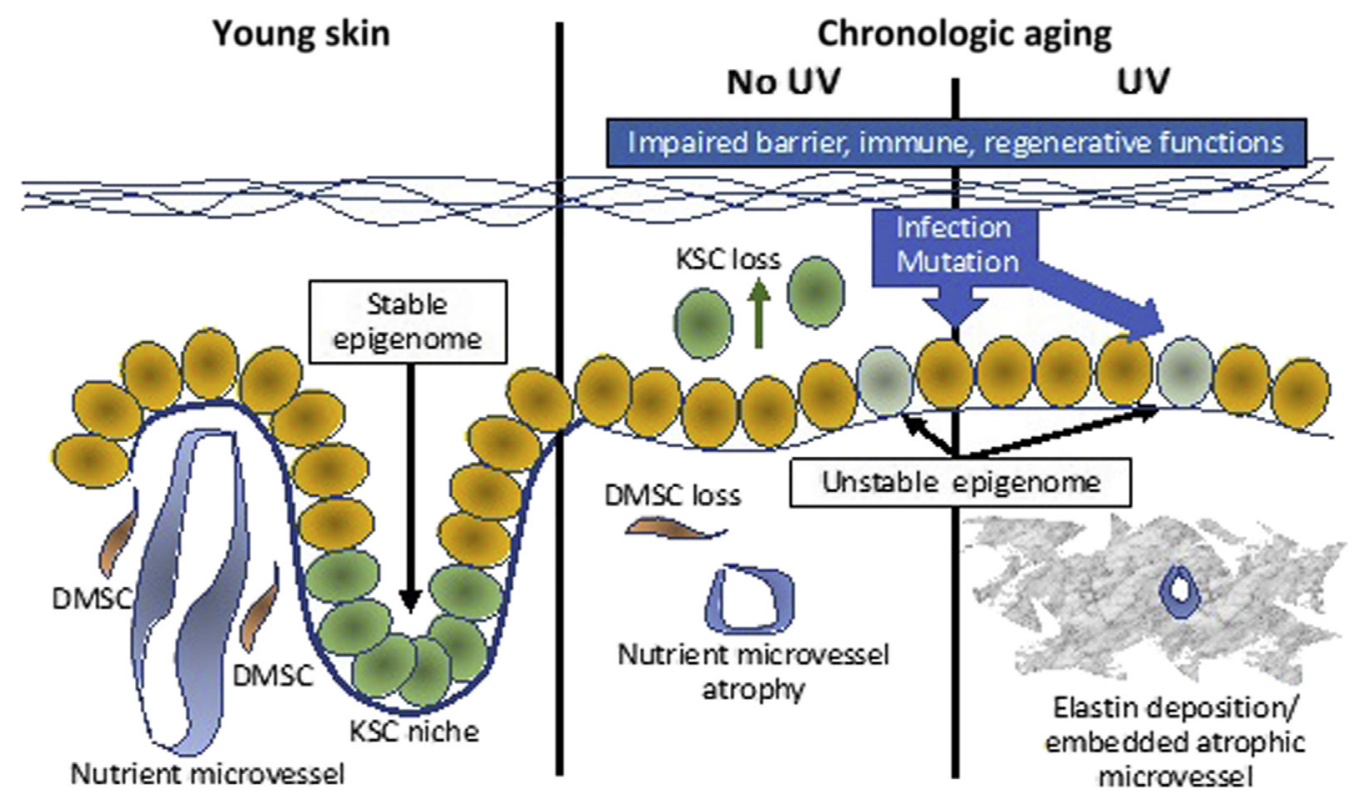

Figure 3 Schematic summary of presumed alterations in skin stem cells with aging. Normal young skin with a stable epigenome maintains keratinocyte stem cells (KSCs) in niches at the tips of dermal papillae and in a microenvironment nourished by dermal papillary microvessels surrounded by dermal mesenchymal stem cells (DMSCs). With chronological aging, epigenomic instability, coupled with UV and environmentally-induced insults, induce mutations, compromise barrier function, and deplete the dermal microenvironment of nutrient vessels and DMSC, resulting in vulnerability to infection and neoplastic transformation. KSCs also become depleted, contributing to epidermal atrophy as a result of loss of the hemidesmosome component, collagen XVII (COL17A1), culminating in stem cell delamination and transepidermal elimination, rather than homeostatic maintenance. ${ }^{47}$

MMPs have been shown to increase damaging intracellular oxidant levels, likely contributing to the aging process of skin and damage to fibroblasts. ${ }^{22}$ The overall effect of decreased collagen in the dermis also results in a lower mechanical tension on fibroblasts of aged skin as compared with younger skin, leading to decreased efficiency of collagen synthesis. ${ }^{25}$ The degradation of collagen and elastin results in loss of strength and resiliency of the skin, manifested clinically as wrinkling and sagging. ${ }^{2}$

The appendages of the skin include sebaceous, apocrine, and eccrine glands in addition to hair follicles. These appendages are responsible for several crucial roles of the skin, including re-epithelialization after injury, thermoregulation, and endocrine function. The sebaceous glands not only produce sebum but also have antibacterial activities, inflammatory functions, and roles in hormone metabolism. 2,26,27 Accordingly, whereas the number of sebaceous glands remains fairly constant over a lifetime, the sebaceous units vary in size depending on the endocrine microenvironment, increasing in size during puberty and becoming smaller after the seventh decade. ${ }^{2,28}$ Sebum levels decrease in post-menopausal females and later in males. Although the rate of sebum production decreases, sebaceous glands become dysfunctional and undergo hyperplasia in aged skin as a compensatory response to falling androgen levels. ${ }^{2}$ Clinically, in addition to sebaceous gland hyperplasia, which may be cosmetically bothersome to the patient, these alterations contribute to xerosis, which is one of the most common manifestations of aged skin.

Interestingly, dermal fibroblasts also have an immune function, with the ability to undergo reactive adipogenesis in response to infectious stimuli. Dermal adipocytes have the ability to secrete antimicrobial peptides such as cathelicidin, and impaired dermal adipogenesis results in increased Staphylococcus aureus infection susceptibility in animal models. ${ }^{29}$ A recent study has shown that this capability is lost with increasing age due to elevated transforming growth factor-beta pathway activation. This results in a profibrotic state and decreased adipogenic capability of dermal fibroblasts, thus impairing adipocyte-mediated immunity in the skin with increasing age. ${ }^{30}$

While both epidermal rete and dermal collagen density are affected by chronological aging in a manner seemingly independent of UV light, sun-exposed aged skin does show one dramatic change: the acquisition of abundant quantities of pathologically altered elastin within the superficial dermis (Figure 1). The precise mechanism(s) responsible for this change remain to be elucidated (synthesis versus defective degradation); however, the alterations are clearly the consequence of UV light exposure. In addition, controlling for the UV absorbent and antioxidant properties of melanin, not all individuals appear to be equally prone to the formation of dermal elastosis as a consequence of chronic sun exposure. Of potential interest, gene expression levels of elastin binding protein, which regulates elastic fiber assembly, and versican, which is integral to both functional and nonfunctional elastic fibers, are influenced by experimental UV exposure and thus may relate to pathways that influence elastin deposition in sun-damaged aged skin. Alternative splicing of the elastin gene as a result of UV irradiation has also been implicated. ${ }^{31}$ Regrettably, most of 
the past focus on elastin deposition/accumulation in UVinduced photoaging has concentrated on skin wrinkles, laxity, and textural anomalies; remarkably little has been explored regarding how striking aggregates of abnormal elastin that accumulate in the superficial dermis might contribute to compromise of structures that become pathologically embedded in it, such as the microvasculature and immune cells within their immediate microenvironment, both critical to the perfusion and protective function of a healthy integument, respectively.

The physiology of cutaneous itching sheds light on the multifactorial altered functionality of aged skin. Xerosis and associated pruritis are the most commonly reported skin complaints of the elderly population. ${ }^{32}$ Chronic idiopathic pruritis most commonly occurs in older individuals, and this condition shares common molecular alterations with inflammatory atopic dermatitis. ${ }^{33}$ In skin of affected patients, type 2 cytokines can directly activate sensory neurons, and chronic itch is associated with neuronal IL-4 receptor alpha and Janus kinase (JAK)-1 signalling. ${ }^{33}$ Interestingly, more recent studies in mice have also demonstrated that xerosis and pruritis in aged skin is associated with a loss of Merkel cells, in association with abnormal scratch behavior responses to mechanical stimuli. ${ }^{34}$

Further exploration of skin aging at an immunohistochemical level reveals even more striking abnormalities not readily appreciated using more conventional preparations. The density and dendricity of epidermal Langerhans cells, for example, is dramatically reduced in both sun- and non-sun-exposed skin of elderly individuals, whereas the number of $\mathrm{T}$ cells in the superficial dermis and epidermis is increased, particularly in sun-exposed elderly skin (Figure 2). Microvessels that stain with CD34 in the superficial dermis and within dermal papillae are diminished in number, small, and lack architectural complexity in aged skin, regardless of sun exposure, and in contrast to the basement membranes of dermal vessels, laminin integral to the epidermal basal lamina becomes faint and attenuated in the skin of old individuals. Finally, aged skin exposed to UV contains numerous basal cells (some likely residual stem cells) that express mutant $\mathrm{p} 53$, indicative of genomic toxicity as a result of solar irradiation.

All of these descriptive findings have a basis in what is already known regarding the molecular pathology of skin aging, and are discussed in greater detail below. Needless to say, however, even cursory immunohistochemical screening reveals striking anomalies in the aged integument that have major functional implications that transcend the cosmetic and that bear directly on the protective role provided by socalled normal skin in the areas of immunity, infection, nutrition, and neoplasia.

\section{Defective Wound Healing and Insights into Aging and Skin Stem Cells}

Chronic ulcers, defined as wounds that fail to heal within a 3 -month period, ${ }^{35}$ are most often associated with diabetes, pressure, or venous/arterial insufficiency. Although these cofactors are more prevalent with increasing age, the fundamental underlying defect in all age-related healing deficiencies may relate to functional and numerical depletion in skin stem cells ${ }^{36}$ that not only blunts tissue repair, but also accounts for skin fragility, atrophy, and the aging phenotype $^{37}$ that itself has functional as well as psychosocial implications. Interest in skin stem cells has developed around a central question: how can skin be induced to regenerate, rather than to heal via contraction and scarring? In the 1980s, Massachusetts Institute of Technology polymer scientist, Ioannis Yannas, ${ }^{38}$ and his then student, Dennis Orgill, advanced a novel hypothesis: skin healing might be enhanced if it were facilitated by the use of a biodegradable scaffold of a defined degradation rate, pore/ fiber size, and chemical composition. Placement of a scaffold that they subsequently developed, and its gradual bioabsorption over time, resulted in healing of full-thickness experimental wounds in rodents that showed significantly less contraction than controls allowed to heal spontaneously. When various time points in the scaffold-facilitated healing response were studied by light and electron microscopy, it was found that the neodermis that resulted was remarkable similar to normal dermis in structure. ${ }^{39,40}$ Whereas control scar tissue was composed of horizontally aligned myofibroblasts, fibroblasts, and collagen fibers permeated by anomalous, perpendicular microvessels, the scaffoldinduced neodermis showed a papillary dermis, reticular dermis, superficial vascular plexus, and associated structures more akin to normal skin. At this time, the notion of dermal mesenchymal stem cells was primordial, although it seemed likely that somehow, the gradually resorbing scaffold was inducing or facilitating a regenerative stem-like pluripotency that was not typical of the much more restricted cellular differentiation pathways of postnatal wound healing.

What was appreciated at that time was that the epidermis contained slow-cycling stem-like cells. In 1982, Lavker and $\mathrm{Sun}^{41}$ noted two distinct populations of basal cells in the epidermis of cynomolgus monkey and human palm skin, one with and one without a serrated basal membrane by electron microscopy, the latter retaining tritiated thymidine labels in pulse-chase experiments. They postulated that the these label-retaining cells represented a stem cell population in the vertebrate epidermis. These cells were concentrated at the tips of epidermal rete ridges, the very structures that become inconspicuous to absent with progressive agerelated epidermal atrophy. ${ }^{42}$ In 1990, Cotsarelis, Sun, and Lavker $^{43}$ extended these observations via the discovery of similar populations of stem-like label-retaining cells in the bulge region of murine and human hair follicles. Although we now know that these follicular stem cells are not the sole contributors to epidermal homeostasis, they have been shown to contribute to cutaneous wound repair. ${ }^{44} \mathrm{~A}$ breakthrough in identification of epithelial stem cells came when Liu and coworkers ${ }^{45}$ identified keratinocyte stem cells in the bulge region of the murine hair follicle to express 
cytokeratin 15 , paving the way for studies that established that human skin and murine lingual rete tips also express this biomarker. ${ }^{46}$

Although age-related epidermal stem cell depletion may be inferred from the atrophy and eventual disappearance of their niche (the rete ridge; see Figure 1), the precise mechanism of this phenomenon has only recently begun to be clarified. Liu and coworkers have focused on the hemidesmosome component, collagen XVII (COL17A1), as a determinant of age-related epidermal stem cell maintenance, with high levels mediating symmetrical stem cell divisions that are capable of outcompeting asymmetrically dividing stem cells characterized by low COL17A1 levels. ${ }^{47}$ Thus, the result of age-related loss of COL171A is stem cell delamination and transepidermal elimination, rather than homeostatic maintenance. Interestingly, shedding of the ectodomain of COL17A1 has been found to be a key step in the signaling of re-epithelialization during wound healing, highlighting a link between stem cell regulation and wound healing. ${ }^{48}$ Age-related pathology to other basement membrane components that may regulate epidermal homeostasis (eg, laminin, see Figure 2) may also play a role in the aging phenotype. ${ }^{49}$ Moreover, there are numerous additional pathways whereby skin stem cell maintenance and fate may be affected during aging. Hair follicle stem cells, for example, are activated to form new terminal hair shafts in association with acquisition of the epigenetic mark, 5hydroxymethylcytosine $(5-\mathrm{hmC}) .{ }^{50}$ This, as well as several other pathways, is consistent with the finding that in contrast to the epidermis, hair follicle stem cells do not decline with age, but rather may lose function that results in enhanced periods of dormancy. ${ }^{51}$ Although factors other than passage of time are responsible for baldness, it has been noted that by age 60 years, two-thirds of men are either bald or have a balding pattern. Another population of skin stem cells, the dermal progenitor cells, are multipotent stem cells that can give rise to multiple cell lineages are responsible for the production of a number of effector molecules including nestin, fibronectin, and vimentin. ${ }^{52}$ Depletion of this stem cell population with age leads to impaired dermal regeneration. Adipocyte stem cells also play an important role in homeostasis and repair, and they have been shown to lose the ability to promote wound healing in aging mice. ${ }^{53} \mathrm{Pe}$ ripheral blood fibrocytes are circulating stem cells that play a role in wound healing. ${ }^{54}$ This cell population has been shown to be important in age-related pulmonary fibrosis, ${ }^{55}$ but their role in the aging of skin remains to be elucidated. Similarly to hair follicle stem cells, it is possible that other mechanisms such as altered signaling and disrupted homeostasis, in addition to stem cell depletion, may contribute to altered stem cell function in aged skin, and this is an ongoing area of research.

In 2003, the laboratory of Natasha and Markus Frank described the regulation of progenitor cell fusion by ABCB5 P-glycoprotein, a novel human ATP-binding cassette transporter. ${ }^{56}$ The ABCB5 transporter was isolated from
CD133-expressing skin cells, and it was subsequently learned that it is expressed by a subpopulation of dermal stem-like cells that possess PD-1-dependent immunoregulatory capacity. ${ }^{57}$ Moreover, the ABCB5-expressing dermal cell population decreases significantly with age in humans. ${ }^{58}$ Additional evidence for a critical role of ABCB5expressing stem cells in regenerative responses comes from recent data implicating ABCB5 as a limbal stem cell gene required for corneal development and repair. ${ }^{59}$

Although comprehensive review and more detailed citations and acknowledgments are beyond the scope of this review, many other laboratories have led the way in the area of skin stem cell biology and the role of stem cells in aging and defective wound healing. Although comprehensive treatment of this pioneering work is not possible, the laboratory of Gonzales et al, ${ }^{60}$ for example, has elucidated fundamental pathways of skin stem cell function, emphasizing the key role these cells and their niches play in regenerative and healing responses. Bickenback and coworkers ${ }^{61}$ have clarified the critical importance of stem cell progeny, transit amplifying cells, in mediating age-related skin alterations. Blanpain and colleagues ${ }^{62}$ have provided enlightening data and commentary regarding skin stem cell dynamics during the healing of murine epidermis. Kretzschmar and Watt ${ }^{63}$ have made seminal contributions regarding epidermal stem cell subpopulation markers that facilitate their study in mammalian skin. And Falanga ${ }^{64}$ has clarified and pioneered the importance of multipotent stem cells as therapeutic modalities in enhancement of wound healing responses. These and other contributions serve to emphasize the fundamental importance of and interplay between the topics of skin stem cells, aging, and defective wound healing, as well as the need for novel and synergistic methods and models to further advance this field toward more effective therapies.

\section{Aging and Skin Immune Cells}

If age-related skin stem cell depletion impacts negatively on both skin structure and function (epidermal atrophy, delayed wound healing), then it is likely that the microenvironment for which stem cells are responsible no longer provides safe harbor to other cell types critical to the protective function of the integument. In 1983, Wayne Streilein ${ }^{65}$ coined the term skinassociated lymphoid tissue (SALT), first recognizing that the skin is in essence a primary immunologic organ involved in constant surveillance to intercept and destroy noxious agents and antigens, often of an infectious nature, in our immediate external environment. Streilein wrote: "nature has provided skin with a unique collection of lymphoid cells, reticular cells, and organized lymphoid organs to deal with these special demands." This discovery that skin harbored resident lymphocytes and dendritic cells revolutionized the field of immunology, and many others have provided corroborative evidence in skin and other tissues over the past 4 decades. ${ }^{66,67}$ 
The discovery of resident memory $\mathrm{T}$ cells in the skin, although rooted in the early descriptions of Streilein, gained momentum with their phenotypic characterization by Stingl and colleagues ${ }^{68}$ in 1990. Although data are lacking regarding the effect of aging on resident CD4- and CD8expressing $\mathrm{T}$ cells in skin, when one considers both the systemic as well as tissue-based T-cell repertoire, it is believed that the latter are susceptible to being lost or impaired in terms of T-cell receptor diversity with age. ${ }^{69}$ Age-related Langerhans cell depletion has been recognized for many years ${ }^{70}$ and is likely in part related to alterations in the epidermal microenvironment upon which Langerhans cells depend for functional, migratory, and replicative programming. ${ }^{71}$ Because immune cell migration in and out of skin is integral to productive and efficient immune responses, the status of the microvasculature as portals for immune cell trafficking also must be considered. With age, dermal vessels are known to show impaired permeability, decreased compliance, decreased density, and anomalous organization (also see Figure 2), and in addition to the impact of such pathologies on epidermal nutrition, dermal immune cell homeostasis is likely to also be affected. ${ }^{72}$

Although aging is generally correlated with depressed skin immunity, is there a situation where aged skin might actually harbor more immune cells? As seen in Figure 2, photoaged skin often contains significant numbers of $\mathrm{T}$ cells, although their function may not be physiologic. In 1988, Lavker and Kligman ${ }^{73}$ coined the term chronic heliodermatitis for photoaged skin (eg, as in the red, thickened skin from sun damaged posterior neck) because this site often contained surprising numbers of lymphocytes and histiocytes. In addition, mast cells also appear to be found in increased numbers in photodamaged skin as compared with sun-protected skin. ${ }^{74}$ Such seemingly aberrant trafficking need not imply a more robust immune capacity, as, for example, accumulation of immunosuppressive regulatory $\mathrm{T}$ cells has been observed in the skin of elderly individuals and has been speculated to potentially relate to skin cancer risk. $^{75,76}$

\section{Skin Aging and Infection}

Aging results in decreased functional capacity of the skin, manifesting as attenuation of its protective effect and immune dysfunction, as described above. Opportunistic skin infections are more common in elderly patients, as are the development of chronic wounds that serve as portals for entry and growth of infectious agents. The classic example of a disease affecting predominantly older patients as a result of immune dysfunction is the varicella zoster virus (VZV) reaction. Latent VZV resides in the sensory nerve ganglia, and reactivation results in the characteristic dermatomal herpes zoster (shingles) rash. Reactivation is due to an age-related impairment of VZV-specific T-cell immunity. This manifests as decreased numbers of circulating VZV-specific, interferon-gamma-producing CD8 T cells, notably in those over the age of 60 years. ${ }^{77}$ Of interest, VZV-specific resident memory CD4-expressing T cells in skin that express CD69 have been found to increase with age, although this may be counterbalanced by concomitant increases with age of skin regulatory $\mathrm{T}$ cells that express FoxP3 and cells that display the inhibitory receptor PD-1. ${ }^{78}$

Beta human papilloma virus (HPV) is significantly more prevalent on the skin of the older population. ${ }^{79}$ The replication of beta HPV, which is implicated in the genesis of cutaneous squamous cell carcinoma (SCC; discussed further below), may be linked to the wound healing process. Wound healing involves re-epithelialization of the injured area from stem cell progenitors and involves the production of reactive oxygen species. Trauma to the skin facilitates HPV infection by allowing propagation of the viral episome in replicating stem cells (see below for detailed discussion). In mice expressing the complete early region of beta HPV-8 under the control of a keratinocyte promoter, papillomas and SCC developed spontaneously in areas where the mice had scratched the skin. ${ }^{80}$ The reactive oxygen species produced during wound healing can induce DNA breaks, possibly contributing to tumorigenesis. One could propose that the wound healing environment is the perfect storm for HPVdriven carcinogenesis, with the ease of access to the stem cell compartment for the HPV virus coupled with the presence of DNA damage resulting in cellular proliferation. Marjolin ulcers are aggressive malignancies that arise from chronic ulcers or wounds, and they occur most frequently in the elderly population. The most common malignancy associated with Marjolin ulcers are SCC. ${ }^{81}$ The mechanism for the development of SCC in chronic wounds in unknown. Many theories have been put forward, including the theory that wounds are immune-privileged sites, with scar tissue hindering normal immune surveillance. ${ }^{82}$ One could speculate that infection of wounded tissue with beta HPV can result in malignant transformation through the stimulation of cellular proliferation in the stem cell compartment coupled with the inhibition of cellular differentiation, thus slowing wound healing. Decreased immune surveillance in the wounded area would also be favorable for HPV persistence. Concurrently, DNA damage induced by oxidative stress in the wound healing environment may also contribute to malignant transformation. If so, this may represent a possible therapeutic target for these aggressive woundassociated tumors, which have a poorer prognosis than conventional cutaneous SCC. ${ }^{83}$

\section{Skin Microbiome and Aging}

The human microbiome is a unique entity in the mammalian world. ${ }^{84}$ The skin plays host to a diverse ecosystem, housing up to a million bacteria per square centimeter of surface area, in addition to viruses and fungi. ${ }^{85}$ In utero, the skin is 
sterile, and becomes colonized during birth and shortly thereafter. ${ }^{86}$ After this initial colonization, the microbiome remains dynamic and varies at different stages of life. Metagenomics, namely 16S RNA sequencing, has allowed the characterization of skin bacteria on a population-wide basis. There are four main bacterial phyla residing on skin, namely the Firmicutes (including Staphylococci), Actinobacteria, Bacteroides, and Proteobacteria, with variations in prevalence depending on body site. ${ }^{86}$ The microbiome flora is largely benevolent and can even play a role in preventing infection through competition for resources and the production of antibacterial compounds. ${ }^{87}$ Microbiomederived factors also affect the host immune system. Studies have shown that surface Staphylococcal cell wall components can directly inhibit host immune responses via modulation of cytokine release from keratinocytes. ${ }^{88} \mathrm{Per}-$ turbations in the skin microbiome have also been implicated in chronic skin conditions such as atopic dermatitis and psoriasis.

Interestingly, there are significant differences in microbiome populations among young and old skin. During puberty, for example, the density of lipophilic bacteria on the skin increases, proportionate to increasing sebum levels, and is lower in elderly skin. ${ }^{86,89}$ Metagenomic studies comparing microbiomes from young and old skin found that the overall microbiota structure was different between the two groups and that there is a decrease in Actinobacteria on older skin. ${ }^{89,90}$ Overall, however, there is increased species diversity in older skin. ${ }^{90}$ Interestingly, one study found that the increased microbiome diversity in older skin is linked to oral flora, a pattern which is also seen in the microbiome of younger patients with atopic dermatitis. ${ }^{91}$ Clearly, the interplay between the microbiome, skin, and the immune system represents a delicate balance that may be more susceptible to disruption with age. A fascinating potential link between the microbiome and the development of cutaneous malignancies has been proposed. There is evidence that the gastrointestinal tract microbiome plays a role in both carcinogenesis and its prevention. ${ }^{92}$

Although there is no definitive evidence currently linking the skin microbiome to skin cancers, this is an exciting emerging area of research. Insights into the potential role of the cutaneous microbiome in skin cancers may lead to novel cancer prevention and treatment strategies in the elderly population, where cutaneous malignancies are common.

\section{Links to Systemic Disease and Cancer}

Basal cell carcinoma (BCC) is the most common human cancer, arising most often in older individuals on sunexposed sites. BCCs harbor UV mutation signatures in tumor suppressor genes including TP53 and in members of the Hedgehog signaling pathway (notably $P T C H$ ). ${ }^{93}$ The importance of UV light exposure and advanced age in the development of $\mathrm{BCC}$ is highlighted by the fact that sporadic
BCC rarely occur in children and they do not occur on mucosal sites. ${ }^{93}$ Although reports of metastatic BCC are rare, it can occur, and recent studies have demonstrated the presence of identical $\mathrm{PTCH}$ mutations in primary BCC and their paired metastatic counterparts. ${ }^{94}$

Although the cumulative damage of a lifetime of UV radiation plays a major role in cutaneous carcinogenesis, the waning immune system also results in an increase of infectionassociated cutaneous malignancies with age, including HPVrelated SCC and Merkel cell polyoma virus (MCV)-associated Merkel cell carcinoma (MCC). Indeed, epidemiologic studies have linked beta HPV to the development of cutaneous SCC in older adults and immunocompromised individuals. ${ }^{79,95}$ In contrast to the high-risk alpha HPV types, beta HPV do not integrate into the host genome, but rather exist as episomes within host cells. One reservoir for cutaneous beta HPV is follicular stem cells, and beta HPV can also induce stemness in basal keratinocytes, enabling viral persistence and accumulation of UV-induced DNA damage. ${ }^{96}$ Beta HPV is actively transcribed in actinic keratoses, but not in cutaneous SCC, ${ }^{97}$ suggesting that beta HPV may be necessary only for the early stages of carcinogenesis in cutaneous SCC. Initial studies showed that expression of beta HPV E6 protein results in an impaired DNA-repair response to UV damage. ${ }^{98}$ Transgenic mouse studies have confirmed this theory by showing that beta HPV facilitates the accumulation of UV-induced DNA damage in tumor suppressor genes including TP53 and NOTCH $1 .{ }^{99}$ Following the development of these mutations, viral oncogenes are dispensable for further tumor growth, supporting a hit and run model of beta HPV oncogenesis in UV-associated cutaneous SCC. ${ }^{99}$

MCC is a rare, but highly aggressive, cutaneous malignancy driven by the oncogenic Merkel cell poliomavirus (MCV) in approximately $80 \%$ of cases. ${ }^{100}$ Although MCV is ubiquitous, the seroprevalence of MCV peaks in the seventh decade, corresponding to the mean age of diagnosis of MCC..$^{101}$ Similar to HPV-associated cutaneous SCC, MCC is more prevalent and occurs at a younger age in immunocompromised patients, highlighting the crucial role of the immune system in prevention of these diseases. ${ }^{102}$ During immune senescence, impaired cytotoxic T-cell and decreased T-cell memory functions result in increased viral replication. UV radiation, another risk factor for MCC, may act synergistically with $\mathrm{MCV}$ in the elderly population by inducing driver mutations in viral oncogenes and promoting immune tolerance in the skin. ${ }^{103}$ Now that is has been well established that oncogenic viruses such as HPV and MCV have evolved to exert their malignant phenotypes in conjunction with UV radiation damage, this interaction may provide possible targets for prevention and treatment of these cancers.

\section{Genetic Factors and Skin Aging}

We have now skimmed the surface of the many implications of skin aging, both chronological (intrinsic) and induced by 
environmental factors such as UV-induced injury, infectious agents, and many other environmental factors (extrinsic). It is difficult to tease out how much of the skin aging phenotype is built in to our cells, and how much is due to external factors, and clearly there exist differences among individuals as to how both intrinsic aging and vulnerabilities to external factors become manifest over time. Said differently, even if one controls for external factors, the many aspects of the skin aging phenotype (with atrophy, defective wound healing, immune suppression, and infection prominently among them) will vary among different people. In this regard, there is evidence that genetic differences may play an important role. Genome-wide association studies, for example, have indicated that SNPs associated with the $M C 1 R$ gene may play a role in skin aging in a manner independent of melanin-related photoprotection. Specifically, it has been suggested that either association with specific SNPs or gene loss-of-function variants may affect skin inflammation ${ }^{104}$ or production of reactive oxygen species in a manner independent of the actual melanin synthesis, ${ }^{105}$ thus promoting the aging phenotype independent of conventional loss of photoprotection.

Epigenetic factors are also likely to come into play in the determination of how rapidly skin aging develops. A number of studies have associated changes in the methylome as a function of skin aging, and experimental knockdown of an enzyme that functions to promote and maintain DNA methylation (DNMT1) resulted in accelerated aging in a murine system. ${ }^{106}$ There also exists evidence that the microRNA, miR-377, may, via DNMT1, regulate gene expression patterns in a way that enhances skin cell demise and contributes to the skin aging profile. ${ }^{107}$ Overall, aging tissues are replete with epigenetic anomalies, including reduction in global heterochromatin, nucleosome loss and remodeling, alterations in histone marks, relocalization of chromatin modifying factors, and global hypomethylation of DNA with hypermethylation of CpG islands. ${ }^{108}$ However, it remains unclear as to whether such changes are the consequence of other processes that drive aging, or they are directly upstream to gene expression pathways that regulate the acquisition of the gradually evolving disease known as aging.

One exciting prospect in the area of epigenetics of aging is the possibility of reprogramming the epigenome, thus returning it to a more normal status with the potential to replenish lost youthfulness. Caloric restriction, for example, may robustly increase longevity in many species through its effects on nutrient-sensing pathways that include AMPK, IGF-1/insulin, mTOR, and sirtuins. ${ }^{108}$ Reversion of murine skin fibroblasts to more stem-like, pluripotent counterparts has been established by Yamanaka and coworkers ${ }^{109}$ using transcription factors Oct3/4, Sox2, Klf4, and c-Myc (OSKM), and a variety of studies now suggest that such approaches in vitro may be capable of reversing age-related epigenetic profiles and phenotypes in vivo. Importantly, short-term cyclic induction of the OSKM factors in a progeria mouse model has been shown to ameliorate the aging phenotype and prolong lifespan. ${ }^{110}$ The potential ways in which such restorative epigenetic approaches affect skin atrophy, wound healing, immune dysfunction, and vulnerability to infection remain to be explored.

A promising epigenetic marker with the potential to unify cancer, skin aging, and age-related extracutaneous disorders is 5-hmC. In 2009, 5-hmC was first established as a novel cysteine modification in mammalian genomes. ${ }^{111,112}$ Global conversion of 5-hmC from 5-methylcytosine (5-mC), a process dependent on the Ten-eleven translocation enzyme family, TET 1-3, typifies somatic cell differentiation and regulates lineage specification. ${ }^{113}$ Because the $5-\mathrm{mC} / 5-\mathrm{hmC}$ switch appears to be fundamental to the epigenetic control of developmental cell plasticity and lineage commitment in a variety of tissues, aberrations in this pathway have the potential to have an impact on many of the phenotypic and functional attributes of skin aging. Indeed, a paradigm for high levels of unregulated cell plasticity and proliferation is cancer, and Lian et $\mathrm{al}^{114}$ have identified loss of 5-hmC as a key feature of the most virulent form of skin malignancy, melanoma. One might, therefore, speculate that the loss of plasticity and proliferative potential that characterizes skin aging may also show changes in 5-hmC expression. Indeed, data from both mice and humans have established increased 5 -hmC levels in association with the aging brain. ${ }^{115}$ However, the status of 5-hmC expression in most other human tissues, including aging skin, remains to be explored.

\section{Conclusions and the Future}

This review has provided only a glimpse into the complex events that account for the disease of skin aging. Beyond UV light and infectious agents, there are numerous other factors that are likely to contribute to the aging skin phenotype. Krutmann and coworkers ${ }^{116}$ have recently emphasized the term skin exposome to describe the totality of potentially deleterious, age-inducing external factors to which skin is exposed during a lifetime. These factors include, in addition to UV radiation, environmental pollutants, stress, nutritional factors, tobacco, temperature-related factors, and even lack of sleep. Such factors, singly or in combination, may have the potential to conspire in a manner that affects the epigenome governing the transcriptional integrity of skin cell DNA, thus pathologically modifying cells, including physiologic stem cells, from the more pristine states that typified their youth (Figure 3). In this respect, it is important to remember that epigenomic alterations that reorganize chromatin and alter gene expression are known to contribute to cellular aging in organisms as basic as budding yeast.

Sinclair and coworkers are pioneering recognition that chromatin factors (sirtuins) such as SIRT1 are key suppressors of epigenetic changes relevant to aging in mammalian species (National Institutes of Health; http:// grantome.com/grant/NIH/R01-AG019719-11Al; last 
accessed November 11, 2019). Sirtuins are highly conserved genes that encode $\mathrm{NAD}^{+}$-dependent deacetylases that increase DNA stability, and it is of potential relevance in that SIRT1 negatively regulates UV-induced alterations likely to contribute to skin stem cell aging and carcinogenesis. $^{117,118}$ Moreover, stem cell aging itself has been shown to be mediated, at least in part, by SIRT $1 .{ }^{119}$ Because epigenetic alterations are reversible, significant pathologic alteration of the exposome mediated via the epigenome could provide transformative insights into how the disease of skin aging develops and progresses, and ultimately how this progression may be arrested and prevented. And because skin has long served as a paradigm for other vital organs, this understanding may enlighten and inform understanding of how other tissues that age, but do not wrinkle, may also be rescued from this forgotten disease.

\section{References}

1. Scully JL: What is a disease? EMBO Rep 2004, 5:650-653

2. Makrantonaki E, Zouboulis CC; German National Genome Research Network 2: The skin as a mirror of the aging process in the human organism-state of the art and results of the aging research in the German National Genome Research Network 2 (NGFN-2). Exp Gerontol 2007, 42:879-886

3. Lener T, Moll PR, Rinnerthaler M, Bauer J, Aberger F, Richter K: Expression profiling of aging in the human skin. Exp Gerontol 2006, 41:387-397

4. Makrantonaki E, Brink TC, Zampeli V, Elewa RM, Mlody B, Hossini AM, Hermes B, Krause U, Knolle J, Abdallah M, Adjaye J, Zouboulis CC: Identification of biomarkers of human skin ageing in both genders. Wnt signalling - a label of skin ageing? PLoS One 2012, 7:1-10

5. Kimball AB, Alora-Palli MB, Tamura M, Mullins LA, Soh C, Binder RL, Houston NA, Conley ED, Tung JY, Annunziata NE, Bascom CC, Isfort RJ, Jarrold BB, Kainkaryam R, Rocchetta HL, Swift DD, Tiesman JP, Toyama K, Xu J, Yan X, Osborne R: Ageinduced and photoinduced changes in gene expression profiles in facial skin of Caucasian females across 6 decades of age. J Am Acad Dermatol 2018, 78:29-39.e7

6. Laga AC, Murphy GF: The translational basis of human cutaneous photoaging: on models, methods, and meaning. Am J Pathol 2009, 174:357-360

7. Murphy GF, Katz S, Kligman AM: Topical tretinoin replenishes CD1a-positive epidermal langerhans cells in chronically photodamaged human skin. J Cutan Pathol 1998, 25:30-34

8. Gupta MA, Gilchrest BA: Psychosocial aspects of aging skin. Dermatol Clin 2005, 23:643-648

9. Salzer MC, Lafzi A, Berenguer-Llergo A, Youssif C, Castellanos A, Solanas G, Peixoto FO, Stephan-Otto Attolini C, Prats N, Aguilera M, Martín-Caballero J, Heyn H, Benitah SA: Identity noise and adipogenic traits characterize dermal fibroblast aging. Cell 2018, 175:1575-1590.e22

10. Stanley JR: Synergy of understanding dermatologic disease and epidermal biology. J Clin Invest 2012, 122:436

11. Kubo A, Nagao K, Amagai M: Epidermal barrier dysfunction and cutaneous sensitization in atopic diseases. J Clin Invest 2012, 122: $440-447$

12. Lavker RM: Structural alterations in exposed and unexposed aged skin. J Invest Dermatol 1979, 73:59-66

13. Harvell JD, Maibach HI: Percutaneous absorption and inflammation in aged skin: a review. J Am Acad Dermatol 1994, 31:1015-1021
14. Biniek K, Kaczvinsky J, Matts P, Dauskardt RH: Understanding ageinduced alterations to the biomechanical barrier function of human stratum corneum. J Dermatol Sci 2015, 80:94-101

15. Branchet MC, Boisnic S, Frances C, Robert AM: Skin thickness changes in normal aging skin. Gerontology 1990, 36:28-35

16. Wurm EMT, Longo C, Curchin C, Soyer HP, Prow TW, Pellacani G: In vivo assessment of chronological ageing and photoageing in forearm skin using reflectance confocal microscopy. Br J Dermatol 2012, 167:270-279

17. Sauermann K, Clemann S, Jaspers S, Gambichler T, Altmeyer P, Hoffmann K, Ennen J: Age related changes of human skin investigated with histometric measurements by confocal laser scanning microscopy in vivo. Skin Res Technol 2002, 8:52-56

18. Waller JM, Maibach HI: Age and skin structure and function, a quantitative approach (II): protein, glycosaminoglycan, water, and lipid content and structure. Skin Res Technol 2006, 12:145-154

19. Varani J, Warner RL, Gharaee-Kermani M, Phan SH, Kang S, Chung JH, Wang ZQ, Datta SC, Fisher GJ, Voorhees JJ: Vitamin A antagonizes decreased cell growth and elevated collagen-degrading matrix metalloproteinases and stimulates collagen accumulation in naturally aged human skin. J Invest Dermatol 2000, 114:480-486

20. Merker K, Sitte N, Grune T: Hydrogen peroxide-mediated protein oxidation in young and old human MRC-5 fibroblasts. Arch Biochem Biophys 2000, 375:50-54

21. Fisher G, Kang S, Varani J, Bata-Csorgo Z, Wan Y, Datta S, Voorhees J: Mechanisms of photoaging and chronological skin aging. Arch Dermatol 2002, 138:1462-1470

22. Fisher GJ, Quan T, Purohit T, Shao Y, Moon KC, He T, Varani J, Kang S, Voorhees JJ: Collagen fragmentation promotes oxidative stress and elevates matrix metalloproteinase-1 in fibroblasts in aged human skin. Am J Pathol 2009, 174:101-114

23. Ghosh K, Capell B: The senescence-associated secretory phenotype: critical effector in skin cancer and aging. J Invest Dermatol 2016 136:2133-2139

24. Varani J, Spearman D, Perone P, Fligiel S, Datta S, Wang Z, Shao Y, Kang S, Fisher G, Voorhees J: Inhibition of type I procollagen synthesis by damaged collagen in photoaged skin and by collagenasedegraded collagen in vitro. Am J Pathol 2001, 158:931-942

25. Varani J, Dame MK, Rittie L, Fligiel SEG, Kang S, Fisher GJ Voorhees JJ: Decreased collagen production in chronologically aged skin. Am J Pathol 2006, 168:1861-1868

26. Fritsch M, Orfanos CE, Zouboulis CC: Sebocytes are the key regulators of androgen homeostasis in human skin. J Invest Dermatol 2001, 116:793-800

27. Zouboulis CC: The human skin as a hormone target and an endocrine gland. Hormones (Athens) 2014, 3:9-26

28. Fenske NA, Lober CW: Structural and functional changes of normal aging skin. J Am Acad Dermatol 1986, 15:571-585

29. Zhang L-J, Guerrero-Juarez CF, Hata T, Bapat SP, Ramos R, Plikus MV, Gallo RL: Dermal adipocytes protect against invasive Staphylococcus aureus skin infection. Science 2015, 347:67-71

30. Zhang L-J, Chen SX, Guerrero-Juarez CF, Li F, Tong Y, Liang Y, Liggins M, Chen X, Chen H, Li M, Hata T, Zheng Y, Plikus MV Gallo RL: Age-related loss of innate immune antimicrobial function of dermal fat is mediated by transforming growth factor beta. Immunity 2019, 50:121-136.e5

31. Weihermann AC, Lorencini M, Brohem CA, de Carvalho CM: Elastin structure and its involvement in skin photoageing. Int J Cosmet Sci 2017, 39:241-247

32. Hahnel E, Lichterfeld A, Blume-Peytavi U, Kottner J: The epidemiology of skin conditions in the aged: a systematic review. J Tissue Viability 2017, 26:20-28

33. Oetjen LK, Mack MR, Feng J, Whelan TM, Niu H, Guo CJ, Chen S, Trier AM, Xu AZ, Tripathi SV, Luo J, Gao X, Yang L, Hamilton SL, Wang PL, Brestoff JR, Council ML, Brasington R, Schaffer A, Brombacher F, Hsieh CS, Gereau RW 4th, Miller B, Chen Z-F, Hu H, Davidson S, Liu O, Kim BS: Sensory neurons co-opt classical 
immune signaling pathways to mediate chronic itch. Cell 2017, 171: 217-228.e13

34. Feng J, Luo J, Yang P, Du J, Kim BS, Hu H: Piezo2 channel-Merkel cell signaling modulates the conversion of touch to itch. Science 2018, 360:530-533

35. Nunan R, Harding KG, Martin P: Clinical challenges of chronic wounds: searching for an optimal animal model to recapitulate their complexity. Dis Model Mech 2014, 7:1205-1213

36. Ahmed ASI, Sheng MH, Wasnik S, Baylink DJ, Lau K-HW: Effect of aging on stem cells. World J Exp Med 2017, 7:1-10

37. Makrantonaki E, Bekou V, Christos CC: Genetics and skin aging. Dermatoendocrinology 2012, 4:280-284

38. Yannas IV, Burke JF, Orgill DP, Skrabut E: Wound tissue can utilize a polymeric template to synthesize a functional extension of skin. Science 1982, 215:174-176

39. Yannas IV, Lee E, Orgill DP, Skrabut EM, Murphy G: Synthesis and characterization of a model extracellular matrix that induces partial regeneration of adult mammalian skin. Proc Natl Acad Sci U S A 1989, 86:933-937

40. Murphy GF, Orgill DP, Yannas I: Partial dermal regeneration is induced by biodegradable collagen-glycosaminoglycan grafts. Lab Invest 1990, 62:305-313

41. Lavker RM, Sun TT: Heterogeneity in epidermal basal keratinocytes: morphological and functional correlations. Science 1982, 215: $1239-1241$

42. Liao YH, Chen SY, Chou SY, Wang PH, Tsai MR, Sun C: Determination of chronological aging parameters in epidermal keratinocytes by in vivo harmonic generation microscopy. Biomed Opt Express 2013, 4:77-88

43. Cotsarelis G, Sun TT, Lavker R: Label-retaining cells reside in the bulge area of pilosebaceous unit: implications for follicular stem cells, hair cycle, and skin carcinogenesis. Cell 1990, 61:1329-1337

44. Ito M, Liu Y, Yang Z, Nguyen J, Liang F, Morris RJ, Cotsarelis G: Stem cells in the hair follicle bulge contribute to wound repair but not to homeostasis of the epidermis. Nat Med 2005, 11:1351-1354

45. Liu Y, Lyle S, Yang Z, Cotsarelis G: Keratin 15 promoter targets putative epithelial stem cells in the hair follicle bulge. J Invest Dermatol 2003, 121:963-968

46. Whitaker-Menezes D, Jones SC, Friedman TM, Korngold R, Murphy GF: An epithelial target site in experimental graft-versus-host disease and cytokine-mediated cytotoxicity is defined by cytokeratin 15 expression. Biol Blood Marrow Transplant 2003, 9:559-570

47. Liu N, Matsumura H, Kato T, Ichinose S, Takada A, Namiki T, Asakawa K, Morinaga H, Mohri Y, De Arcangelis A, GerogesLabouesse E, Nanba D, Nishimura EK: Stem cell competition orchestrates skin homeostasis and ageing. Nature 2019, 568:344-350

48. Jacków J, Löffek S, Nyström A, Bruckner-Tuderman L, Franzke CW: Collagen XVII shedding suppresses re-epithelialization by directing keratinocyte migration and dampening mTOR signaling. J Invest Dermatol 2016, 136:1031-1041

49. Amano S: Possible involvement of basement membrane damage in skin photoaging. J Investig Dermatol Symp Proc 2009, 14:2-7

50. Leavitt D, Wells M, Abarzua P, Murphy GF, Lian CG: Differential distribution of the epigenetic marker 5-hydroxymethylcytosine occurs in hair follicle stem cells during bulge activation. J Cutan Pathol 2019, 46:327-334

51. Schultz MB, Sinclair DA: When stem cells grow old: phenotypes and mechanisms of stem cell aging. Development 2016, 143:3-14

52. Zouboulis CC, Adjaye J, Akamatsu H, Moe-Behrens G, Niemann C: Human skin stem cells and the ageing process. Exp Gerontol 2008, 43:986-997

53. Ma N, Qiao C, Zhang W, Luo H, Zhang X, Liu D, Zang S, Zhang L, Bai J: Original research: adipose-derived stem cells from younger donors, but not aging donors, inspire the host self-healing capability through its secreta. Exp Biol Med (Maywood) 2017, 242:68-79

54. Kao HK, Chen B, Murphy GF, Li Q, Orgill DP, Guo L: Peripheral blood fibrocytes: enhancement of wound healing by cell proliferation, re-epithelialization, contraction, and angiogenesis. Ann Surg 2011, 254:1066-1074

55. Sueblinvong V, Neveu WA, Neujahr DC, Mills ST, Rojas M, Roman J, Guidot D: Aging promotes pro-fibrotic matrix production and increases fibrocyte recruitment during acute lung injury. Adv Biosci Biotechnol 2014, 5:19-30

56. Frank NY, Pendse SS, Lapchak PH, Margaryan A, Shlain D, Doeing C, Sayegh MH, Frank MH: Regulation of progenitor cell fusion by ABCB5 P-glycoprotein, a novel human ATP-binding cassette transporter. J Biol Chem 2003, 278:47156-47165

57. Schatton T, Yang J, Kleffel S, Uehara M, Barthel SR, Schlapbach C, Zhan Q, Dudeney S, Mueller H, Lee N, de Vries JC, Meier B, Vander Beken S, Kluth MA, Ganss C, Sharpe AH, Waaga-Gasser AM, Sayegh MH, Abdi R, Scharffetter-Kochanek K, Murphy GF, Kupper TS, Frank NY, Frank MH: ABCB5 identifies immunoregulatory dermal cells. Cell Rep 2015, 12:1564-1574

58. de Vries J, Meier-Schiesser B, Jiang D, Frank N, Vander Beken S, Ziouta Y, Kluth A, Ganss C, Frank M, Scharffetter-Kochanek K: Towards further characterization of ABCB5+ mesenchymal stem cells in the ageing skin. 42nd Annual Meeting of the Arbeitsgemeinschaft Dermatologische Forschung; 2015, Abstract P023

59. Ksander BR, Kolovou PE, Wilson BJ, Saab KR, Guo Q, Ma J, McGuire SP, Gregory MS, Vincent WJB, Perez VL, Cruz-Guilloty F, Kao W, Call MK, Tucker BA, Zhan Q, Murphy GF, Lathrop KL, Alt C, Mortensen L, Lin CP, Zieske JD, Frank MH, Frank N: ABCB5 is a limbal stem cell gene required for corneal development and repair. Nature 2014, 511:353-357

60. Gonzales KAU, Fuchs E: Skin and its regenerative powers: an alliance between stem cells and their niche. Dev Cell 2017, 43:387-401

61. Winter MC, Bickenbach JR: Aging epidermis is maintained by changes in transit-amplifying cell kinetics, not stem cell kinetics. J Invest Dermatol 2009, 129:2541-2543

62. Aragona M, Dekoninck S, Rulands S, Lenglez S, Mascré G, Simons BD, Blanpain C: Defining stem cell dynamics and migration during wound healing in mouse skin epidermis. Nat Commun 2017, 8:14684

63. Kretzschmar K, Watt FM: Markers of epidermal stem cell subpopulations in adult mammalian skin. Cold Spring Harb Perspect Med 2014, 4:a013631

64. Falanga V: Stem cells in tissue repair and regeneration. J Invest Dermatol 2012, 132:1538-1541

65. Streilein J: Skin-associated lymphoid tissues (SALT): origins and functions. J Invest Dermatol 1983, 80:12s-16s

66. Murphy GF, Liu V: The Dermal Immune System. Edited by Bos J. In Ski Immune Syst. New York: CRC Press, 1997. pp. 347-363

67. Takamura S: Niches for the long-term maintenance of tissue-resident memory T cells. Front Immunol 2018, 9:1214

68. Foster CA, Yokozeki H, Rappersberger K, Koning F, Volc-Platzer B, Rieger A, Coligan JE, Wolff K, Stingl G: Human epidermal T cells predominately belong to the lineage expressing $\alpha / \beta$ T cell receptor. J Exp Med 1990, 171:997-1013

69. Goronzy JJ, Weyand CM: Successful and maladaptive T cell aging. Immunity 2017, 46:364-378

70. Gilhar A, Pillar T, David M, Eidelman S: Melanocytes and Langerhans cells in aged versus young skin before and after transplantation onto nude mice. J Invest Dermatol 1991, 96:210-214

71. Clayton K, Vallejo AF, Davies J, Sirvent S, Polak ME: Langerhans cells-programmed by the epidermis. Front Immunol 2017, 8:1676

72. Bentov I, Reed M: The effect of aging on the cutaneous microvasculature. Microvasc Res 2015, 100:25-31

73. Lavker RM, Kligman A: Chronic heliodermatitis: a morphologic evaluation of chronic actinic dermal damage with emphasis on the role of mast cells. J Invest Dermatol 1988, 90:325-330

74. Braverman IM, Fonferko E: Studies in cutaneous aging: I. The elastic fiber network. J Invest Dermatol 1982, 78:434-443

75. Agius E, Lacy KE, Vukmanovic-Stejic M, Jagger AL, Papageorgiou AP, Hall S, Reed JR, Curnow SJ, Fuentes-Duculan J, 
Buckley CD, Salmon M, Taams LS, Krueger J, Greenwood J, Klein N, Rustin MHA, Akbar AN: Decreased TNF- $\alpha$ synthesis by macrophages restricts cutaneous immunosurveillance by memory CD4+ T cells during aging. J Exp Med 2009, 206:1929-1940

76. Fessler J, Ficjan A, Duftner C, Dejaco C: The impact of aging on regulatory T-cells. Front Immunol 2013, 4:231

77. Weinberg A, Lazar AA, Zerbe GO, Hayward AR, Chan ISF, Vessey R, Silber JL, MacGregor RR, Chan K, Gershon AA, Levin MJ: Influence of age and nature of primary infection on varicella-zoster virus-specific cell-mediated immune responses. J Infect Dis 2010, 201:1024-1030

78. Vukmanovic-Stejic M, Sandhu D, Seidel JA, Patel N, Sobande TO, Agius E, Jackson SE, Fuentes-Duculan J, Suárez-Fariñas M, Neil A, Mabbott NA, Lacy KE, Ogg G, Nestle FO, Krueger JG, Rustin MHA, Akbar AN: The characterization of varicella zoster virus-specific T cells in skin and blood during ageing. J Invest Dermatol 2015, 135: $1752-1762$

79. Hampras SS, Giuliano AR, Lin H-Y, Fisher KJ, Abrahamsen ME, Sirak BA, Iannacone MR, Gheit T, Tommasino M, Rollison DE: Natural history of cutaneous human papillomavirus (HPV) Infection in men: the HIM study. PLoS One 2014, 9:e104843

80. Hufbauer M, Akgül B: Molecular mechanisms of human papillomavirus induced carcinogenesis. Viruses 2017, 9:187

81. Xiang F, Song H-P, Huang Y-S: Clinical features and treatment of 140 cases of Marjolin's ulcer at a major burn center in southwest China. Exp Ther Med 2019, 17:3403-3410

82. Fazeli MS, Lebaschi AH, Hajirostam M, Keramati MR: Marjolin's ulcer: clinical and pathologic features of 83 cases and review of literature. Med J Islam Repub Iran 2013, 27:215-224

83. Iqbal FM, Sinha Y, Jaffe W: Marjolin's ulcer: a rare entity with a call for early diagnosis. BMJ Case Rep 2015, 2015. bcr2014208176

84. Ross AA, Müller KM, Weese JS, Neufeld JD: Comprehensive skin microbiome analysis reveals the uniqueness of human skin and evidence for phylosymbiosis within the class Mammalia. Proc Natl Acad Sci U S A 2018, 115:E5786-E5795

85. Chen YE, Tsao H: The skin microbiome: current perspectives and future challenges. J Am Acad Dermatol 2013, 69:143-155

86. Grice El, Segre JA: The skin microbiome. Nat Rev Microbiol 2011, 9:244-253

87. Sanford JA, Gallo RL: Functions of the skin microbiota in health and disease. Semin Immunol 2013, 25:370-377

88. Lai Y, Di Nardo A, Nakatsuji T, Leichtle A, Yang Y, Cogen AL, Wu Z-R, Hooper LV, Schmidt RR, von Aulock S, Radek KA, Huang C, Huang C-M, Ryan AF, Gallo RL: Commensal bacteria regulate Toll-like receptor 3-dependent inflammation after skin injury. Nat Med 2009, 15:1377-1382

89. Jugé R, Rouaud-Tinguely P, Breugnot J, Servaes K, Grimaldi C, Roth M-P, Coppin H, Closs B: Shift in skin microbiota of Western European women across aging. J Appl Microbiol 2018, 125:907-916

90. Shibagaki N, Suda W, Clavaud C, Bastien P, Takayasu L, lioka E, Kurokawa R, Yamashita N, Hattori Y, Shindo C, Breton L, Hattori M: Aging-related changes in the diversity of women's skin microbiomes associated with oral bacteria. Sci Rep 2017, 7:10567

91. Chng KR, Tay ASL, Li C, Ng AHQ, Wang J, Suri BK, Matta SA, McGovern N, Janela B, Wong XFCC, Sio YY, Au BV, Wilm A, De Sessions PF, Lim TC, Tang MBY, Ginhoux F, Connolly JE, Lane EB, Chew FT, Common JEA, Nagarajan N: Whole metagenome profiling reveals skin microbiome-dependent susceptibility to atopic dermatitis flare. Nat Microbiol 2016, 1:16106

92. Ahn J, Sinha R, Pei Z, Dominianni C, Wu J, Shi J, Goedert JJ, Hayes RB, Yang L: Human gut microbiome and risk for colorectal cancer. J Natl Cancer Inst 2013, 105:1907-1911

93. Pellegrini C, Maturo MG, Di Nardo L, Ciciarelli V, Gutiérrez GarcíaRodrigo C, Fargnoli MC: Understanding the molecular genetics of basal cell carcinoma. Int J Mol Sci 2017, 18:2485

94. Laga AC, Schaefer IM, Sholl LM, French CA, Hanna J: Metastatic basal cell carcinoma. Am J Clin Pathol 2019, 152:706-717
95. Wang J, Aldabagh B, Yu J, Arron ST: Role of human papillomavirus in cutaneous squamous cell carcinoma: a meta-analysis. J Am Acad Dermatol 2014, 70:621-629

96. Hufbauer M, Biddle A, Borgogna C, Gariglio M, Doorbar J, Storey A, Pfister H, Mackenzie I, Akgul B: Expression of betapapillomavirus oncogenes increases the number of keratinocytes with stem cell-like properties. J Virol 2013, 87:12158-12165

97. Arron ST, Ruby JG, Dybbro E, Ganem D, DeRisi J: Transcriptome sequencing demonstrates that human papillomavirus is not active in cutaneous squamous cell carcinoma. J Invest Dermatol 2011, 131: $1745-1753$

98. Hufbauer M, Cooke J, van der Horst GTJ, Pfister H, Storey A, Akgül B: Human papillomavirus mediated inhibition of DNA damage sensing and repair drives skin carcinogenesis. Mol Cancer 2015, 14:183

99. Viarisio D, Müller-Decker K, Accardi R, Robitaille A, Durst M, Beer K, Jansen L, Flechtenmacher C, Bozza M, Harbottle R, Voegele C, Ardin M, Zavadil J, Caldeira S, Gissman L, Tommasino M: Beta HPV38 oncoproteins act with a hit-and-run mechanism in ultraviolet radiation-induced skin carcinogenesis in mice. PLoS Pathog 2018, 14:e1006783

100. Feng H, Shuda M, Chang Y, Moore P: Clonal integration of a polyomavirus in human merkel cell carcinoma. Science 2008, 319:1096-1100

101. Viscidi RP, Rollison DE, Sondak VK, Silver B, Messina JL, Giuliano AR, Fulp W, Ajidahun A, Rivanera D: Age-specific seroprevalence of merkel cell polyomavirus, BK virus, and JC virus. Clin Vaccine Immunol 2011, 18:1737-1743

102. Becker JC: Merkel cell carcinoma. Ann Oncol 2010, 21(Suppl 7): vii81-vii85

103. Bhatia S, Afanasiev O, Nghiem P: Immunobiology of merkel cell carcinoma: implications for immunotherapy of a polyomavirusassociated cancer. Curr Oncol Rep 2011, 13:488-497

104. Liu F, Hamer MA, Deelen J, Lall JS, Jacobs L, Van Heemst D, Murray PG, Wollstein A, De Craen AJM, Uh HW, Zeng C, Hofman A, Uitterlinden AG, Houwing-Duistermaat JJ, Pardo LM, Beekman M, Slagboom PE, Nijsten T, Kayser M, Gunn DA: The MC1R gene and youthful looks. Curr Biol 2016, 26:1213-1220

105. Elfakir A, Ezzedine K, Latreille J, Ambroisine L, Jdid R, Galan P, Hercberg S, Gruber F, Malvy D, Tschachler E, Guinot C: Functional MC1R-gene variants are associated with increased risk for severe photoaging of facial skin. J Invest Dermatol 2010, 130:1107-1115

106. Flood KS, Houston NA, Savage KT, Kimball AB: Genetic basis for skin youthfulness. Clin Dermatol 2019, 37:312-319

107. Xie HF, Liu YZ, Du R, Wang B, Chen MT, Zhang YY, Deng HL, Li J: miR-377 induces senescence in human skin fibroblasts by targeting DNA methyltransferase 1. Cell Death Dis 2017, 8:e2663

108. Kane AE, Sinclair D: Epigenetic changes during aging and their reprogramming potential. Crit Rev Biochem Mol Biol 2019, 54:61-83

109. Takahashi K, Yamanaka S: Induction of pluripotent stem cells from mouse embryonic and adult fibroblast cultures by defined factors. Cell 2006, 126:663-676

110. Ocampo A, Reddy P, Martinez-Redondo P, Platero-Luengo A, Hatanaka F, Hishida T, Li M, Lam D, Kurita M, Beyret E, Araoka T, Vazquez-Ferrer E, Donoso D, Roman JL, Xu J, Rodriguez Esteban C, Nuñez G, Nuñez Delicado E, Campistol JM, Guillen I, Guillen P, Izpisua Belmonte JC: In vivo amelioration of age-associated hallmarks by partial reprogramming. Cell 2016, 167:1719-1733.e12

111. Kriaucionis S, Heintz N: The nuclear DNA base 5hydroxymethylcytosine is present in purkinje neurons and the brain. Science 2009, 324:929-930

112. Tahiliani M, Koh KP, Shen Y, Pastor WA, Bandukwala H, Brudno Y, Agarwal S, Iyer LM, Liu DR, Aravind L, Rao A: Conversion of 5methylcytosine to 5-hydroxymethylcytosine in mammalian DNA by MLL partner TET1. Science 2009, 324:930-935

113. Bocker MT, Tuorto F, Raddatz G, Musch T, Yang FC, Xu M, Lyko F, Breiling A: Hydroxylation of 5-methylcytosine by TET2 maintains the active state of the mammalian HOXA cluster. Nat Commun 2012, 3:818 
114. Lian CG, Xu Y, Ceol C, Wu F, Larson A, Dresser K, Xu W, Tan L, Hu Y, Zhan Q, Lee CW, Hu D, Lian BQ, Kleffel S, Yang Y, Neiswender J, Khorasani AJ, Fang R, Lezcano C, Duncan LM, Scolyer RA, Thompson JF, Kakavand H, Houvras Y, Zon LI, Mihm MC, Kaiser UB, Schatton T, Woda BA, Murphy GF, Shi YG: Loss of 5-hydroxymethylcytosine is an epigenetic hallmark of Melanoma. Cell 2012, 150:1135-1146

115. Haffner MC, Chaux A, Meeker AK, Esopi DM, Gerber J, Pellakuru LG, Toubaji A, Argani P, Iacobuzio-Donahue C, Nelson WG, Netto GJ, De Marzo AM, Yegnasubramanian S: Global 5-hydroxymethylcytosine content is significantly reduced in tissue stem/progenitor cell compartments and in human cancers. Oncotarget 2011, 2:627-637
116. Krutmann J, Bouloc A, Sore G, Bernard BA, Passeron T: The skin aging exposome. J Dermatol Sci 2017, 85:152-161

117. Cao C, Lu S, Kivlin R, Wallin B, Card E, Bagdasarian A, Tamakloe T, Wang W-J, Song X, Chu W-M, Kouttab N, Xu A, Wan Y: SIRT1 confers protection against UVB- and $\mathrm{H} 2 \mathrm{O} 2$-induced cell death via modulation of p53 and JNK in cultured skin keratinocytes. J Cell Mol Med 2009, 13:3632-3643

118. Ming M, Soltani K, Shea CR, Li X, He YY: Dual role of SIRT1 in UVB-induced skin tumorigenesis. Oncogene 2015, 34:357-363

119. Yu A, Dang W: Regulation of stem cell aging by SIRT1 - linking metabolic signaling to epigenetic modifications. Mol Cell Endocrinol 2017, 455:75-82 